\title{
NIST gas standards containing volatile organic compounds in support of ambient air pollution measurements
}

\author{
G. C. Rhoderick \\ Analytical Chemistry Division, Chemical Science and Technology \\ Laboratory, National Institute of Standards and Technology (NIST), \\ Gaithersburg, Maryland, USA
}

\begin{abstract}
Since the late 1970s the National Institute of Standards and Technology (NIST), Gaithersburg, Maryland, USA, has been developing and supplying reference materials (RMs) in support of gas measurements for measuring ambient air pollution. These RMs have been developed for federal and state governments in the United States (US), such as the US Environmental Protection Agency (EPA) and the State of California Air Resources Board (CARB), as well as academia, research laboratories such as the National Center for Atmospheric Research (CARB), and other laboratories around the world. Many of these volatile organic compounds (VOCs) pose health concerns and are monitored at ground level to assist U.S. government agencies in assessing the need for emission studies and controls. Ozone is also a ground level pollutant of great concern. Hydrocarbons are ozone precursors and are measured to track, in particular, automobile emissions. RMs are split into two groups containing either multicomponent mixtures of VOCs or non-methane hydrocarbons (NMHCs). Typically these RMs are produced at the $0.02-10 \mathrm{nmol} / \mathrm{mol}(\mathrm{ppb})$ level. The research into the preparation and stability of such chemical compounds contained in gas mixtures has led to the development of two Standard Reference Materials (SRMs); a 30component VOC (SRM 1804) and 18-component NMHC (SRM 1800) at $5 \mathrm{nmol} / \mathrm{mol}$ per component. NIST has participated in international comparisons with other National Metrology Institutes (NMIs) through bilaterals and CCQM key and pilot comparisons for many of these VOCs and NMHCs. Results of these comparisons have shown equivalency among these NMIs, helping to underpin their measurement and standards claims. Development of these SRMs and RMs, as well as the international comparisons will be discussed.

Keywords: standard reference material (SRM), reference material (RM), volatile organic compounds (VOCs), non-methane hydrocarbons (NMHC), primary standard mixtures (PSMs), air pollution measurements.
\end{abstract}




\section{Introduction}

Over the past 30 years, the need and demand for accurate standards containing trace levels $[<10 \mathrm{nmol} / \mathrm{mol}(\mathrm{ppb})]$ of toxic organic vapor in a matrix gas has increased. Federal and state environmental programs have been implemented requiring the monitoring of compounds from automobile exhaust, industrial emissions, hazardous waste sites and incineration to name a few. In the United States (US) the US Environmental Protection Agency (US-EPA) has identified many volatile organic compounds (VOCs) that represent possible health risks [1]. Several of these compounds are documented as potential carcinogens [2,3]. Included in the classification of VOCs are non-halogenated, non-methane hydrocarbons (NMHC) primarily from automobile exhaust. These hydrocarbons (NMHCs) are precursors to the formation of ozone $\left(\mathrm{O}_{3}\right)$ and are major contributors to photochemical smog [4]. This has increased the interest in measuring the levels of VOCs and NMHCs at ground level and the upper atmosphere. The measurement data aids regulators in determining the level of reduction in ambient concentrations required to achieve national ambient air quality standards for ozone [5,6]. Measurement data aids in developing control measures and as input for urban atmosphere modelling $[7,8]$.

The ability to intercompare adequately the host of laboratories that analyze VOCs and NMHCs depends on the provision of standards with certified concentrations with low levels of uncertainty. Primary and secondary standards are necessary to correlate data accurately, a prerequisite for adequate regulation of toxic organic pollution. In addition, specialty gas companies preparing VOC/NMHC gas mixtures for customers prefer to have a traceability link to a nationally recognized standard. The amount-of-substance fraction (concentration) of a chemical species in a gas mixture can be accurately determined by comparing the unknown mixture with a primary standard mixture (PSM) prepared by an absolute method such as gravimetry. Comparative techniques referenced to PSMs must be used to certify other mixtures as Standard Reference Materials (SRMs).

There have been several techniques developed and used to prepare gas standards, or calibration standards, for VOCs. A procedure for the gravimetric preparation of volatile organic compounds in a gas matrix was previously developed at the National Institute of Standards and Technology (NIST) [9,10]. Up to 30 - 40 liquid analytes (if one is extremely careful) can be accurately weighed into a $30 \mathrm{~L}$ aluminium gas cylinder. More than 70 carbon based compounds have been studied for feasibility and stability in gas mixtures. Standards have been developed containing varying numbers of compounds (130) and concentrations $10 \mathrm{pmol} / \mathrm{mol}$ to $10 \mu \mathrm{mol} / \mathrm{mol}$. NIST has used this procedure to develop more than 200 in-house primary standard mixtures (PSMs). These PSMs have then been used to certify over 200 Reference Materials (RM) for the US EPA, the state of California Air Resources Board (CARB), and many other laboratories and university research groups in the USA and internationally. A total of 475 Standard Reference Materials (SRMs) have been developed and certified. This paper will discuss two of the most complex VOC/NMHC SRMs 
developed and a complex RM. Results from international comparisons with other National Metrology Institutes (NMIs) for some of the VOC/NMHCs will also be discussed.

\section{SRM development}

Twelve different NIST SRMs for VOCs and NMHCs have been developed over the past 20 years of which there are currently 2 available. They include SRM 1804, a 30 component VOC and SRM 1800, a 19 component NMHC, both at $5 \mathrm{nmol} / \mathrm{mol}$ per component. The most often requested VOC gas standard is for EPA Method TO-14 (organics, semi-volatile and volatile). The TO-14 list varies from 39-45 organic analytes. NIST settled on a subset of 30 analytes so as to create a simple chromatogram using one analytical column which would result in no co-elution of compounds.

\subsection{SRM 1804 - VOCs}

The 30 component VOC SRM 1804 was developed and certified in 2003. A detailed description of the development of this SRM has been published [11]. Using the previously mentioned techniques and procedures for preparing gravimetric standards, 4 PSMs were developed and used to certify SRM 1804. Table 1 gives the concentration and expanded uncertainty $(95 \%$ confidence interval) in $\mathrm{nmol} / \mathrm{mol}$, for each of the $30 \mathrm{VOCs}$ in a representative mixture. The majority of the components have expanded uncertainties of $\leq \pm 5.0 \%$. The analytical data have larger uncertainties for the higher molecular mass components resulting in larger certified uncertainties. Each of the samples in this SRM 1804 lot was individually certified.

A key component of the quality assurance program at NIST includes stability checks of SRMs at appropriate time intervals. This SRM was recertified in 2007 after stability analysis were preformed using the original and newly prepared PSMs. Figure 1 shows the 4 year stability data for the SRM lot standard (LS) 1804-C-01. The LS is a cylinder prepared at the same time as the SRM lot and is retained at NIST. All of the cylinders comprising the lot are compared to the LS. The LS is assumed to be representative of the SRM lot.

\subsubsection{SRM 1800 - NMHCs}

The original 15 component NMHC SRM 1800 was developed in 1993, the current 18 component SRM was certified in 2003. The same techniques and procedures for PSM development and SRM preparation and certification were used for both SRM 1800 lots and a detailed description has been published [12]. Five PSMs were developed and used to certify the current SRM 1800. Table 2 lists the compounds with their certified concentrations and expanded uncertainties at the $95 \%$ confidence interval. All but one of the components has an uncertainty of $\leq \pm 2.9 \%$ with decane having an uncertainty of $\pm 5.6 \%$. 
Table 1: Certified concentrations and uncertainties for a representative SRM 1804 sample.

\begin{tabular}{lc}
\hline \multicolumn{1}{c}{ Analyte } & $\begin{array}{c}\text { Concentration and Uncertainty in } \\
\text { nmol/mol }(95 \%)\end{array}$ \\
\hline Dichlorodifluoromethane & $4.43 \pm 0.09(2.0 \%)$ \\
Chloromethane & $4.83 \pm 0.10(2.1 \%)$ \\
1,2-Dichlorotetrafluoroethane & $4.25 \pm 0.09(2.1 \%)$ \\
Vinyl chloride & $3.42 \pm 0.27(7.9 \%)$ \\
Chloroethane & $5.14 \pm 0.10(1.9 \%)$ \\
Trichlorofluoromethane & $5.26 \pm 0.11(2.1 \%)$ \\
1,1-Dichloroethene & $5.27 \pm 0.11(2.1 \%)$ \\
Dichloromethane & $5.41 \pm 0.11(2.0 \%)$ \\
1,1-Dichloroethane & $5.42 \pm 0.11(2.0 \%)$ \\
cis-1,2-Dichloroethene & $5.30 \pm 0.11(2.1 \%)$ \\
Chloroform & $5.39 \pm 0.11(2.1 \%)$ \\
1,1,1-Trichloroethane & $5.34 \pm 0.11(2.1 \%)$ \\
Carbon tetrachloride & $5.34 \pm 0.11(2.1 \%)$ \\
Benzene & $5.33 \pm 0.11(2.1 \%)$ \\
Trichloroethylene & $5.42 \pm 0.11(2.0 \%)$ \\
1,2-Dichloropropane & $5.35 \pm 0.11(2.1 \%)$ \\
Toluene & $5.38 \pm 0.11(2.0 \%)$ \\
1,1,2-Ttrichloroethane & $5.30 \pm 0.21(2.1 \%)$ \\
Tetrachloroethylene & $5.37 \pm 0.11(2.1 \%)$ \\
Chlorobenzene & $5.33 \pm 0.11(2.1 \%)$ \\
Ethylbenzene & $5.32 \pm 0.11(2.1 \%)$ \\
para-Xylene & $5.42 \pm 0.11(2.0 \%)$ \\
ortho-Xylene & $5.03 \pm 0.20(4.0 \%)$ \\
1,1,2,2-Tetrachloroethane & $5.51 \pm 0.28(5.1 \%)$ \\
1,3,5-Trimethylbenzene & $5.34 \pm 0.22(4.1 \%)$ \\
1,2,4-Trimethylbenzene & $5.52 \pm 0.22(4.0 \%)$ \\
1,3-Dichlorobenzene & $5.52 \pm 0.28(5.1 \%)$ \\
1,2-Dichlorobenzene & $5.48 \pm 0.28(5.1 \%)$ \\
1,2,4-Ttrichlorobenzene & $4.88 \pm 0.49(10.0 \%)$ \\
Hexachloro-1,3-butadiene & $4.97 \pm 0.50(10.1 \%)$ \\
\hline &
\end{tabular}

Three major stability analyses have been performed on the original SRM 1800 certified in 1993. The data has shown 11 years of continued stability for this SRM. Figure 2 illustrates the stability of LS 1800-01-A (original SRM 1800). The spread in the data points for any given hydrocarbon is about $2 \%$, which is within the uncertainty. An interesting observation is that the last stability analysis in 2004 results in concentrations that are closer to the original value than at any other time. 


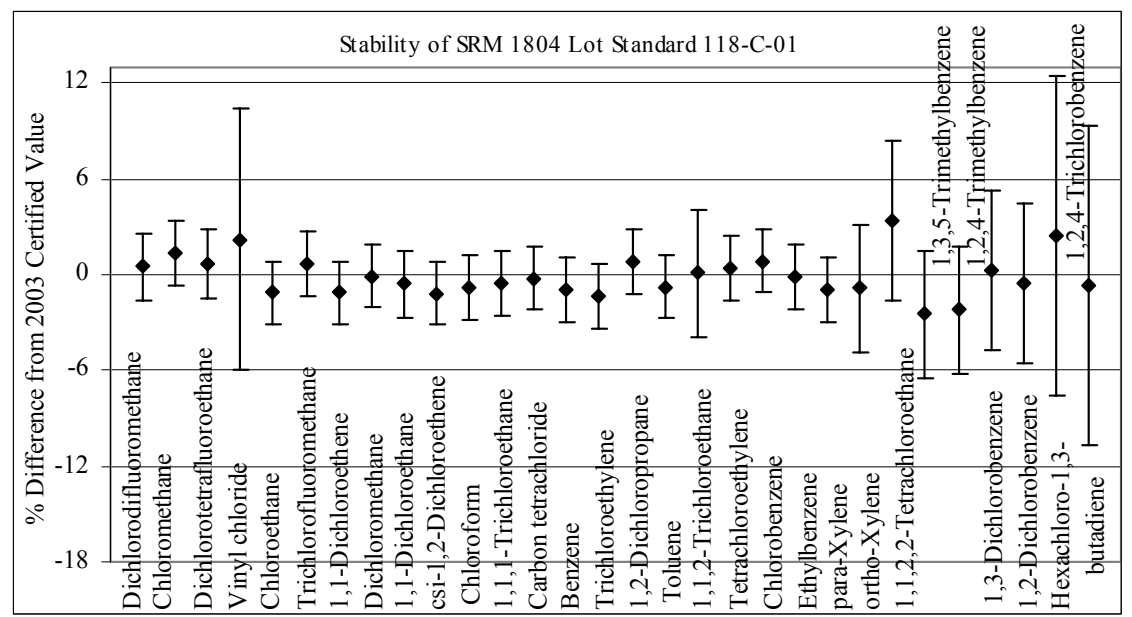

Figure 1: $\quad$ Stability Data for SRM 1804 Lot Standard 1804-C-01 from 2007 analysis.

Table 2: Certified concentrations and uncertainties for a representative SRM 1800 sample.

\begin{tabular}{lc}
\hline \multicolumn{1}{c}{ Analyte } & $\begin{array}{r}\text { Concentration and Uncertainty } \\
\text { in nmol/mol }(95 \%)\end{array}$ \\
\hline Ethane & $5.35 \pm 0.11(2.0 \%)$ \\
Propane & $5.64 \pm 0.11(2.0 \%)$ \\
Propene & $5.40 \pm 0.11(2.0 \%)$ \\
iso-Butane & $5.68 \pm 0.11(1.9 \%)$ \\
n-Butane & $5.54 \pm 0.11(2.0 \%)$ \\
iso-Butene & $5.68 \pm 0.12(2.1 \%)$ \\
iso-Pentane & $5.24 \pm 0.11(2.1 \%)$ \\
n-Pentane & $5.31 \pm 0.11(2.0 \%)$ \\
1-Pentene & $5.13 \pm 0.15(2.9 \%)$ \\
n-Hexane & $5.30 \pm 0.11(2.1 \%)$ \\
n-Heptane & $5.39 \pm 0.11(2.1 \%)$ \\
Benzene & $5.50 \pm 0.11(2.0 \%)$ \\
iso-Octane & $5.32 \pm 0.11(2.1 \%)$ \\
n-Octane & $5.14 \pm 0.11(2.1 \%)$ \\
Toluene & $5.23 \pm 0.15(2.9 \%)$ \\
Nonane & $4.98 \pm 0.14(2.8 \%)$ \\
ortho-Xylene & $4.96 \pm 0.12(2.4 \%)$ \\
Decane & $4.82 \pm 0.27(5.6 \%)$ \\
\hline
\end{tabular}

2.1.1.1 Multi-component RM Many of the gas mixtures for ambient air pollution monitoring are prepared as RMs. They can be very complex with very different concentrations. One such VOC gas mixture used for ambient toxic 
calibration by CARB contains 27 components with concentrations varying from 0.020 to $5.0 \mathrm{nmol} / \mathrm{mol}$ as listed in table 3, along with stability data. Several VOCs, highlighted in bold, have shown decreases outside or just at the original uncertainty limits. Although carbon tetrachloride has demonstrated stability at $5 \mathrm{nmol} / \mathrm{mol}$, at this concentration there has been a major decrease of $>51 \%$. NIST has observed good stability for the major percentage of VOCs at $5 \mathrm{nmol} / \mathrm{mol}$. However, there are a few that consistently exhibit stability problems.

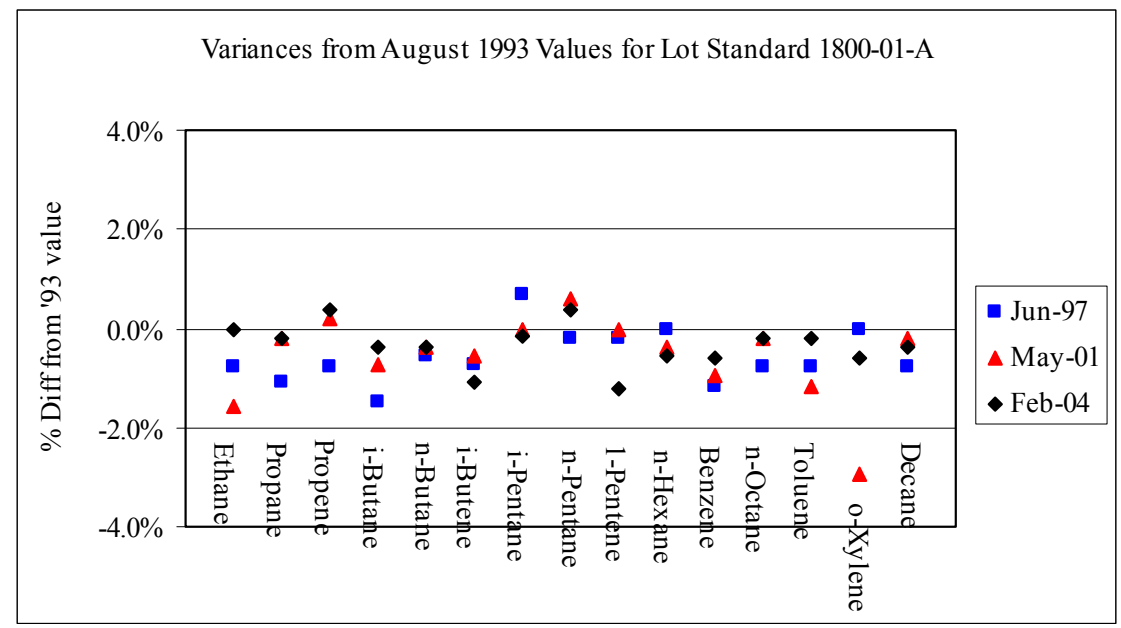

Figure 2: Stability Data for SRM 1800 Lot Standard 1800-01-A.

\subsection{Comparison of standards between National Metrology Institutes} (NMIs) Only a few NMIs have or are currently developing standards and RMs of VOC/NMHCs. The National Physical Laboratory (NPL) in the United Kingdom and the National Metrology Institute (NMi) in the Netherlands analyzed a representative NIST PSM for the original SRM 1800. Figure 3 illustrates the results of that comparison. The agreement was within the uncertainty for almost all of the analytes and demonstrates equivalency among these NMIs. Results of other comparisons for VOC gas mixtures between NMIs have been published [13-15].

\section{Conclusions}

These RM and SRM mixtures containing nmol/mol multi-component VOC/NMHC have allowed laboratories to use traceable gas mixtures to determine the levels of these components in ground and atmospheric environments. In general, most of these compounds have exhibited good stability in gas mixtures contained in treated aluminium gas cylinders, and those 
compounds that have shown decreases over time are limited. Many combinations of compounds and concentrations are possible, and concentration demands for gas mixtures will continue to trend lower.

Table 3: Certified concentrations and uncertainties for a complex RM VOC gas mixture.

\begin{tabular}{|c|c|c|}
\hline \multirow[b]{3}{*}{ Analyte $^{a}$} & \multicolumn{2}{|c|}{$\begin{array}{l}\text { Concentration and Uncertainty } \\
\text { in } \mathrm{nmol} / \mathrm{mol}(95 \%)\end{array}$} \\
\hline & Original Value & Recertified Value \\
\hline & February 2004 & February 2007 \\
\hline Dichlorodifluoromethane & $1.01 \pm 0.03$ & $1.01 \pm 0.02$ \\
\hline Vinyl chloride & $0.60 \pm 0.01$ & $0.60 \pm 0.02$ \\
\hline 1,3-Butadiene & $1.49 \pm 0.12$ & $1.36 \pm 0.14$ \\
\hline Bromomethane & $2.03 \pm 0.17$ & $1.89 \pm 0.20$ \\
\hline Trichlorofluoromethane & $1.77 \pm 0.06$ & $1.77 \pm 0.07$ \\
\hline Dichloromethane & $1.86 \pm 0.11$ & $1.86 \pm 0.11$ \\
\hline Chloroform & $0.25 \pm 0.01$ & $0.25 \pm 0.02$ \\
\hline $1,1,2-$ & $0.53 \pm 0.02$ & $0.53 \pm 0.02$ \\
\hline Trichlorotrifluoroethane & & \\
\hline 1,1,1-Trichloroethane & $1.33 \pm 0.04$ & $1.33 \pm 0.04$ \\
\hline Carbon tetrachloride & $0.17 \pm 0.01$ & $0.072 \pm 0.04$ \\
\hline 1,2-Dichloroethane & $0.44 \pm 0.02$ & $0.44 \pm 0.02$ \\
\hline Benzene & $2.59 \pm 0.07$ & $2.59 \pm 0.05$ \\
\hline Trichloroethylene & $0.44 \pm 0.02$ & $0.44 \pm 0.02$ \\
\hline cis-1,3-Dichloropropene & $2.68 \pm 0.03$ & $2.37 \pm 0.45$ \\
\hline trans-1,3- & $2.68 \pm 0.09$ & $1.64 \pm 0.67$ \\
\hline Dichloropropene & & \\
\hline Toluene & $4.38 \pm 0.08$ & $4.38 \pm 0.15$ \\
\hline Tetrachoroethylene & $0.52 \pm 0.03$ & $0.52 \pm 0.02$ \\
\hline 1,2-Dibromoethane & $0.95 \pm 0.03$ & $0.93 \pm 0.11$ \\
\hline Chlorobenzene & $1.81 \pm 0.04$ & $1.81 \pm 0.05$ \\
\hline Ethylbenzene & $2.76 \pm 0.07$ & $2.76 \pm 0.06$ \\
\hline para-Xylene & $2.62 \pm 0.06$ & $2.62 \pm 0.06$ \\
\hline meta-Xylene & $2.65 \pm 0.12$ & $2.65 \pm 0.07$ \\
\hline ortho-Xylene & $2.70 \pm 0.09$ & $2.70 \pm 0.06$ \\
\hline Styrene & $3.7 \pm 0.2$ & $2.3 \pm 0.6$ \\
\hline 1,3-Dichlorobenzene & $2.59 \pm 0.09$ & $2.50 \pm 0.21$ \\
\hline 1,4-Dichlorobenzene & $2.75 \pm 0.07$ & $2.63 \pm 0.19$ \\
\hline 1,2-Dichlorobenzene & $2.69 \pm 0.07$ & $2.54 \pm 0.28$ \\
\hline
\end{tabular}

${ }^{a}$ Analytes and concentrations in bold represent those compounds that are exhibiting decreases (either marginally or significantly) in concentration over time. 


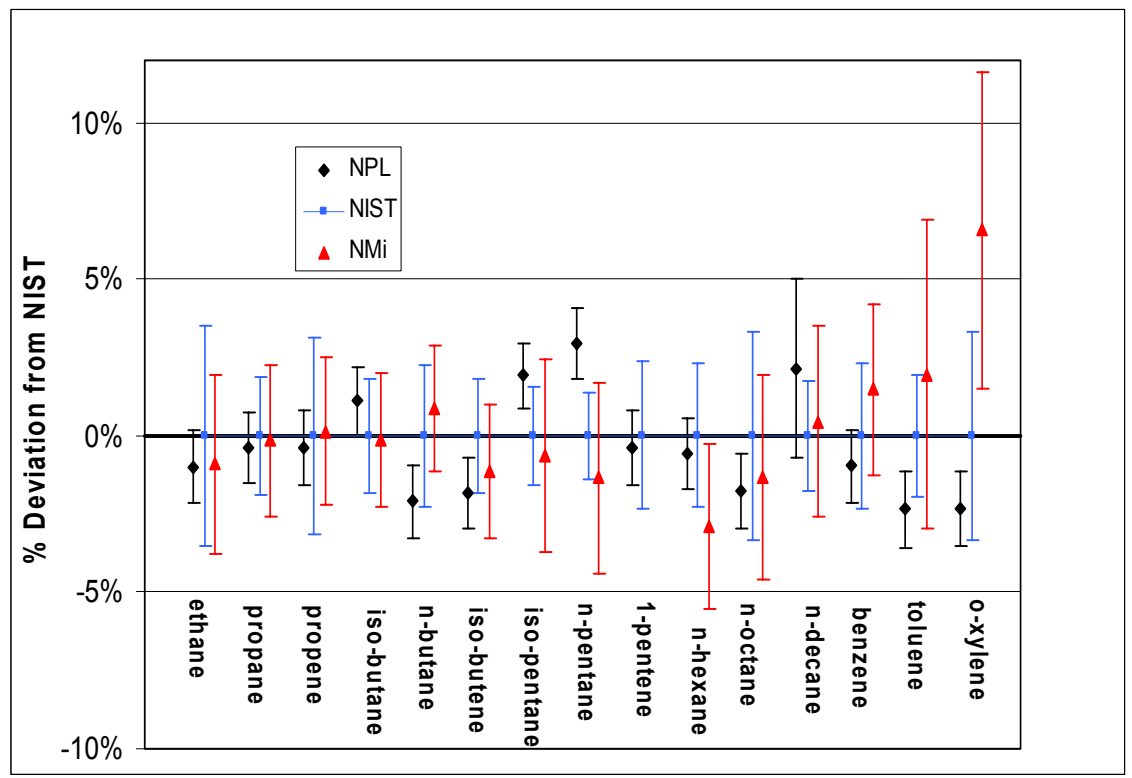

Figure 3: Analytical results for comparison of SRM 1800 representative standard with NIST, NPL and NMi.

\section{References}

[1] IRAC Monographs on the Evaluation of Carcinogenic Risk of Chemicals to Man: International Agency for Research on Cancer. Health Organization: Geneva, Switzerland, 1, pp. 53-65, 1972 and 7, pp. 203-216, 291-305, 1974.

[2] von Lehmden, D.J., Conference on Recent Developments in Methods for Toxics in the Atmosphere, Boulder, CO, 1987.

[3] New health data may affect clean air rules, $C \& E N$, 68(4), pp. 5, 1990.

[4] Haagerr-Smit, A.J., Chemistry and Physiology of Los Angeles Smog, Industrial and Engineering Chemistry, 44, pp.1342-1346, 1952.

[5] Guidance for Collection of Ambient Non-methane Organic Compounds (NMOC) Data for Use in 1982 Ozone SIP Development and Network Design and Siting Criteria for the NMOC and $\mathrm{NO}_{\mathrm{x}}$ Monitors, EPA-450/480-011, 1980.

[6] Singh, H.B., Guidance for the Collection and Use of Ambient Hydrocarbon Species Data in Development of Ozone Control Strategies, EPA-450/4-80$008,1980$.

[7] Derwent, R.G., Hov, O., Computer Modeling Studies of the Impact of Vehicle Exhaust Emission Controls on Photochemical Air- Pollution Formation in the United Kingdom, Environmental Science and Technology, 14, pp. 1360-1366, 1980. 
[8] Whitten, G.Z., Hugo, H., Killus, J.P., The Carbon-Bond Mechanism-A Condensed Mechanism for Photochemical Smog, Environmental Science \& Technology, 14, pp. 690-700, 1980.

[9] Schmidt, W.P., Rook, H.L., Preparation of Gas Cylinder Standards For Measurement of Trace Levels of Benzene and Tetrachloroethylene, Analytical Chemistry, 55, pp.290-294, 1983.

[10] Rhoderick, G.C., Zielinski, W.L., Jr., Preparation of Accurate Multicomponent Gas Standards of VOCs in the Low-Parts-per-Billion Range, Analytical Chemistry, 60, pp. 2454-2466, 1988.

[11] Rhoderick, G.C., Development of a NIST Standard Reference Material Containing Thirty Volatile Organic Compounds at $5 \mathrm{nmol} / \mathrm{mol}$ in Nitrogen, Analytical Chemistry, 78(9), pp. 3125-3132, 2006.

[12] Rhoderick, G.C., Development of a 15 Component Hydrocarbon gas Standard Reference Material at $5 \mathrm{nmol} / \mathrm{mol}$ in Nitrogen, Fresenius Journal of Analytical Chemistry, 359, pp. 477-483, 1997.

[13] Guenther, F.R., Rhoderick, G.C., et al.; Key Comparison CCQM-K7: Benzene, Toluene, Ethylbenzene, m-Xylene and o-Xylene in Nitrogen, Metrologia, 39, 2002.

[14] Guenther, F.R., Rhoderick, G.C., et al, Key Comparison CCQM-K10: Benzene, Toluene, o-Xylene in Nitrogen, Metrologia, 39, 2002.

[15] Kato, K., Maruyama, M., Kim, J.S., Heo, G.S., Kim, Y-D., Guenther, F.R., Rhoderick, G.C., van der Veen, A.M.H., Baldan, A., Milton, M.J.T., Vargha, G., Brookes, C., Konopelko, L., Kustikov, Y., Vishnyakov, I., Final Report on key comparison CCQM-K22: Benzene,chloroform,dichloromethane,trichloroethylene, tetrachloroethylene,1,2-dichloroethane,1,3-butadiene and vinyl chloride in nitrogen, Metrologia 44, 08006, 2007. 